\title{
Percursos neurobiológicos do processo de decision- making: o papel das emoções no comportamento humano
}

Neurobiological pathways in the decision-making process: the role of emotions in human behavior

Recorridos Neurobiológicos del Proceso de Decision-Making: el Papel de las Emociones en el Comportamiento Humano

Leonardo Ferreira Almada*

\section{Resumo}

Este artigo visa a defender a significação de algumas hipóteses neurobiológicas - acerca das relações dos raciocínios morais com as emoções - que se propóem depreender um caminho privilegiado para a compreensão objetiva e em bases causais do comportamento humano e do percurso neural que envolve o processo de decision-making. Ao mesmo tempo, proponho defender que, se processos emocionais e processos cognitivos têm percursos neurais próprios e particulares, também éverdade que, no âmbito dos raciocínios morais e da regulação do comportamento, há uma cooperação e integração funcional significativa, a qual inviabiliza a tradicional dicotomia ou subordinação entre processos cognitivos e processos emocionais na constituição do comportamento ético. Com base em consulta bibliográfica e busca pelo sistema Medline, pretendo demonstrar certa equiparação entre a neurociência do comportamento e certos postulados de Aristóteles, que já defende que nem todos os atos humanos são efetivamente livres.

Palavras-chave: neurociência afetiva; emoções e raciocínios morais; processos emocionais e cognitivos; neuroética; epistemologia das neurociências.

\begin{abstract}
This article aims to advocate the significance of some neurobiological hypotheses - concerning the relations between moral reasoning and emotions - which propose to devise a special way to an objective and causal understanding of human behavior, as well as of the neural
\end{abstract}

\footnotetext{
Texto recebido em novembro de 2009 e aprovado para publicação em junho de 2010.

* Doutor em Filosofia, professor efetivo adjunto I da Faculdade de Filosofia da Universidade Federal de Goiás (UFG), bolsista do Fapesp. E-mail: leonardo.f.almada@gmail.com.
} 
pathway that involves the decision-making process. At the same time, it argues that if emotional and cognitive processes have their own neural pathways, is also true that, in the context of moral reasoning and behavior regulation, there is significant functional cooperation and integration, which undermine the traditional dichotomy or subordination between cognitive and emotional processes in the constitution of ethical behavior. Based on the literature review and the Medline system search, the paper intends to demonstrate some equivalence between Behavioral Neuroscience and some of Aristotle's postulates, which argue that not all human actions are effectively free.

Keywords: affective neuroscience; emotions and moral reasoning; emotional and cognitive processes; neuroethics; epistemology of neurosciences.

\section{Resumen}

Este artículo visa defender la significación de algunas hipótesis neurobiológicas - acerca de las relaciones de los raciocinios morales con las emociones - que se proponen desprender un camino privilegiado para la comprensión objetiva y en bases causales del comportamiento humano y del recorrido neural que envuelve el proceso de decision-making. A la vez, propongo defender que, si procesos emocionales y procesos cognitivos tienen recorridos neurales propios y particulares, también es verdad que, en el ámbito de los raciocinios morales y de la regulación del comportamiento, hay una cooperación e integración funcional significativa, la cual inviabiliza la tradicional dicotomía o subordinación entre procesos cognitivos y procesos emocionales en la constitución del comportamiento ético. A partir de consulta bibliográfica y búsqueda por el sistema Medline, pretendo demostrar cierta equiparación entre la Neurociencia del Comportamiento y correctos postulados de Aristóteles, que ya defiende que ni todos los actos humanos son efectivamente libres.

Palabras-clave: neurociencia afectiva; emociones y raciocinios morales; procesos emocionales y cognitivos; neuroética; epistemología de las neurociencias.

\section{Apresentação do problema: a posição aristotélica}

problema da tomada de decisão (decision-making) e, subsequentemente, da voluntariedade ou não da ação humana constitui, desde os gregos, uma das questões mais debatidas na história da Filosofia, da Psicologia e das Neurociências. Sem dúvida, é com Aristóteles que a questão ganha efetiva notoriedade e visibilidade na história do pensamento ocidental. Em vista da 
conceituação acerca das condições de possibilidade de uma vida virtuosa e, portanto, eudaimonica (eudaimonia), Aristóteles, grosso modo, proclamou a necessidade de uma vida conforme a função que é mais própria ao homem enquanto ser racional: trata-se de uma vida conforme a razão, ou, em outras palavras, uma atividade da alma conforme a virtude mais perfeita, o que implica o disciplinamento das paixões. Em tal compreensão, como se vê, está suposta a defesa de que, por meio da escolha efetiva, deve o homem atingir o seu objetivo como criatura racional, isto é, sua função de criatura dotada de inteligência e vontade. Sobre isso, diz Aristóteles (2000a, p. 156):

Sempre que está em nosso poder o fazer, está também o não fazer, e sempre que está em nosso poder o não, está o sim, de modo que, se está em nosso poder o agir quando é belo, o estará também quando é vergonhoso, e se está em nosso poder o não agir quando é belo, o estará, assim mesmo, para agir quando é vergonhoso. E se está em nosso poder fazer o belo e o vergonhoso e, igualmente, o não fazê-lo, e nisso radica o ser bons ou maus, estará em nosso poder o ser virtuoso ou vicioso.

Sendo assim, é voluntariamente que os homens são virtuosos ou continentes, bem como é voluntariamente que esses mesmos homens podem ser incontinentes ou se tornarem viciosos, quando, então, não será mais o homem voluntário no mesmo sentido estrito: o hábito, que é o grande regulador da ação, acaba subsumindo o homem a uma voluntariedade que exclui a escolha da ação quando voltado para práticas más. Ora, ainda que todos os atos morais, tanto os virtuosos quanto os viciosos, sejam voluntários, somente o homem virtuoso pode efetivamente escolher. Desse modo, as atitudes viciosas são voluntárias, mas jamais poderão ser consideradas como atos de escolha:

Havendo definido o voluntário e o involuntário, devemos tratar agora da escolha, a que parece ser mais apropriada à virtude [...]. É evidente que a escolha é algo voluntário, mas não é o mesmo que isso, dado que o voluntário tem maior extensão; pois, do voluntário participam também as crianças e outros animais, mas não da escolha, e às ações feitas impulsivamente chamamos voluntárias, mas não escolhidas. [...] o homem incontinente atua por apetite, mas não por escolha; o continente, ao contrário, atua escolhendo, e não por apetite. Ademais, o apetite é contrário à escolha, mas não o apetite ao apetite (Aristóteles, 2000a, p. 185).

Isso porque a escolha é um princípio de ação moral, ou um desejo deliberado acerca do que se sabe ser realmente bom. Fora dos limites do 
entendimento, não pode haver mais que uma mera opinião. Segue-se daí que "sem intelecto, sem reflexão e sem disposição ética não há escolha, pois o bem agir e seu contrário não podem existir sem reflexão e sem caráter" (Aristóteles, 2000a, p. 271). Mas, com efeito, se o ato humano, pelo qual os homens podem ser felizes ou não, é voluntário no sentido de escolha efetiva, segue-se, em consequência, a ideia de que o agir moral pressupõe a responsabilidade e a autonomia. E, sem essa suposição, não seria possível o estabelecimento de qualquer doutrina moral. Para evitar esse problema, Aristóteles (2000a, p. 192) afirma que:

Tudo isso parece estar confirmado, tanto pelos indivíduos em particular como pelos próprios legisladores: efetivamente, eles castigam e tomam represálias dos que têm cometido más ações sem ter sido levados pela força ou pela ignorância de que eles mesmos não são responsáveis, e, em troca, honram aos que fazem o bem, para estimular a estes e impedir a ação dos outros. E, certamente, nada nos exorta a fazer o que não depende de nós nem é voluntário.

E são justamente as ações virtuosas e as viciosas que distinguem aqueles para os quais se dirigem os elogios, daqueles que, por sua vez, são merecedores da repreensão e do castigo. É por isso que Aristóteles destaca o vício e a incontinência como algumas das principais disposições ou inclinações morais que devem ser evitadas na formação do ente moral (Aristóteles, 2000a, p. 290). O homem incontinente é aquele que:

Busca os prazeres excessivos - e, por sua vez, evita as dores da pobreza, a fome, a sede, o calor, o frio e todas as sensações penosas do tato e do gosto - e isso não por escolha deliberada, senão contrariando ela e sua razão (Aristóteles, 2000a, p. 301).

$\mathrm{O}$ incontinente, ao contrário do que tem o domínio sobre si mesmo por meio da razão e que, por isso mesmo, é continente, é aquele que, em decorrência da subserviência aos mandos das paixões, não consegue exercer o controle sobre seus apetites. Assim sendo, o incontinente, bem como o licencioso, é aquele que sempre age contra a reta razão. No entanto, deve-se ressaltar que o incontinente não é como o licencioso, visto que, ainda que a paixão o domine e o faça agir contra sua reta razão, ele jamais deixará de se convencer de que não deve seguir tais prazeres desenfreadamente. Dessa asserção se seguem alguns outros pontos fundamentais: (I) o incontinente age voluntariamente, quando o ato voluntário é pressuposto de qualquer ação moral; (II) mas a sua escolha, diferentemente da do licencioso, "é boa, de modo que só é mal pela metade"; e, finalmente (III) não é injusto, "pois não 
põe embustes" (Aristóteles, 2000a, p. 313). Todavia, ainda que seja melhor do que o licencioso, o incontinente é incapaz de ater-se ao que ele mesmo delibera. Por conseguinte, o que distingue o continente do incontinente é o atender ou não às suas resoluções, que, em si mesmas, são boas. Tendo isso em vista, o incontinente se parece com "uma cidade que decreta tudo o que se deve decretar e que tem boas leis, mas não usa nenhuma delas". O licencioso, em troca, "é semelhante a uma cidade que faz uso das leis, mas das más". Em outra passagem, Aristóteles destaca que, o que separa o incontinente do licencioso é o fato de que "ambos perseguem os prazeres corporais, mas o dissoluto crê que deve fazê-lo e o incontinente não” (Aristóteles, 2000a, p. 313).

De fato, com tal conceituação e sistematização, Aristóteles sem dúvida lança uma série de problemas para a posteridade. Sem dúvida, Aristóteles parece, em face do que sabemos hoje, ter atribuído uma significação exacerbada à capacidade que tem o homem de efetivamente realizar escolhas. Porém sua compreensão de que o voluntário tem uma significação muito mais ampla que a escolha parece extremamente atual, pois Aristóteles soube reconhecer que há fatores internos e externos que parecem inviabilizar a liberdade humana. Com efeito, a neurociência da ética, ou do comportamento ético, tem se dedicado a averiguar as bases neurobiológicas das tomadas de decisão. Recentes descobertas acerca do funcionamento neuroanatômico, neuroquímico e neurofuncional dos mamíferos em geral, além de toda contribuição da psicologia fisiológica, e especialmente do behaviorismo metodológico e radical, trazem consigo argumentos convincentes quanto à crença tão defendida por boa parte da História da Filosofia de que o homem é caracterizado pela capacidade de autonomia e deliberação, ou ainda, de que um juízo moral é uma questão de escolhas puramente racionais diante de situações ou objetos contrários.

\section{Apresentação do problema sob o prisma das Neurociências}

Por suas características, a orientação teórica proposta neste artigo se insere em um dos mais promissores e fecundos campos de atuação de nosso século, a epistemologia das Neurociências. Trata-se de um campo de atuação multidisciplinar que congrega epistemologia e ética filosóficas, ciências cognitivas, evolucionismo e Neurociências, e que assimila resultados e postulados de diversas ciências da mente. A associação entre esses inúmeros ramos do saber não se justifica apenas pela colaboração recíproca que de fato mantêm entre si; mais que isso, certos avanços conceituais e empíricos das Neurociências dependem estreitamente dessa conjunção de conhecimentos e 
perspectivas. Por outro lado, significativos avanços nas pesquisas com modelos éticos têm decorrido dos esforços das ciências da mente em correlacionar inúmeros aspectos do comportamento a específicas atividades neuroquímicas, neurofuncionais e neuroelétricas inerentes à atividade cerebral.

Sem que necessariamente precise ir de encontro às filosóficas perspectivas éticas da contemporaneidade, as Neurociências parecem açambarcá-las, além de dar conta do instigante problema da alteridade e justificar os aspectos empíricos que estão na base de inúmeros comportamentos que nos distinguem dos outros primatas. Em contrapartida, novos e depurados problemas éticos surgiram e vêm surgindo no âmbito dos valores socialmente aceitos e rejeitados, mediante a pesquisa científica do cérebro e as implicações geradas pelo exitoso e, ao mesmo tempo, controverso uso das novas tecnologias de neuroimagem, como o EEG (eletroencefalograma), a MRI (magnetic resonance imaging), a fMRI (Functional magnetic resonance imaging), o PET (positron emission tomography), o SPECT (single photon emission computed tomography) e as técnicas imunocitoquímicas, cuja função é averiguar as linguagens químicas dos circuitos neuronais. Decerto são essas novas tecnologias e os correspondentes estudos, teorias e modelos científicos que criam circunstâncias no interior das quais as questões éticas se defrontam com novos e reiterados desafios.

\section{A natureza moral do homem}

Há mais de dois milênios, o debate sobre a natureza moral do homem ocupa posição privilegiada nas discussões envolvendo filósofos, teólogos, juristas e moralistas. Apenas recentemente, porém, foi possível atingir um conhecimento empírico da organização neural que corresponde ao comportamento moral. Segundo Jorge Moll et al. (2003, p. 299), esse avanço qualitativo para um conhecimento estruturado em sólidas bases empíricas muito se deve à análise de pacientes com "drásticas mudanças no comportamento social" em função de "lesões cerebrais adquiridas", assim como ao "estudo do comportamento normal e patológico com aparelhos de neuroimagem funcional e estrutural”. Daí porque acreditam que o uso dos aparelhos de neuroimagem funcional e estrutural tem mostrado que grande parte do "comportamento humano é implicitamente moral e resulta necessariamente de múltiplos processos psicológicos e neurobiológicos que teoricamente se situam sobre um continuum entre os extremos da prossociabilidade e da antissociabilidade" (Moll, Oliveira-Souza \& Eslinger, 2003, p. 299).

$\mathrm{O}$ reconhecimento de que as emoções morais exercem um poderoso efeito sobre o comportamento humano tem estimulado e incentivado a realização 
de inúmeros testes, assim como a formulação de inúmeras hipóteses sobre o comportamento de alguns indivíduos que desenvolveram ou adquiriram um comportamento antissocial como resultado de específicos danos cerebrais. De fato, ninguém pode negar que tais pesquisas estão ainda em fase inicial; entretanto, os resultados já existentes desde o final do século XX e início do século atual parecem sugerir engenhosas e instigantes soluções para certos atributos neurobiológicos exclusivamente humanos no comportamento ético, que parecem orientar certos padrões de conduta.

A descoberta de que (I) grande parte do comportamento humano supóe a influência das emoções no raciocínio moral e de que (II) a formação do pensamento moral resulta de específicos e múltiplos processos psicológicos e neurobiológicos parece evidenciar que, em tempos de século XXI, as Neurociências se propõem consolidar a promessa que vem realizando desde meados do século XX: depreender, da relação dos raciocínios morais com as emoções, um caminho privilegiado para a compreensão objetiva e em bases causais do comportamento humano e do percurso neural que envolve o processo de decision-making.

Um estudo polêmico e relativamente recente indica que os estados emocionais influenciam seletivamente a atividade neural que se relaciona com a cognição no córtex pré-frontal (CPF) lateral: isso indica uma forte integração e interação emoção-cognição, fato particularmente rejeitado por grande parte da tradição filosófica ocidental e que pode descontextualizar de maneira significa a consideração da tomada de decisão como um atributo do espírito livre. Tais estudos, porém, geram grande interesse para o estudo filosófico e científico do comportamento ético, principalmente pelas relações que estabelecem entre raciocínios morais e emoções e pela influência que tal conjunção exerce nas orientações comportamentais.

Consoante os proponentes da pesquisa, emoção e cognição contribuem de maneira conjunta e igual para o controle do pensamento e do comportamento: todo comportamento e todo pensamento moral supõe relações intrínsecas entre processos emocionais e processos cognitivos, no âmbito neurofuncional, neuroanatômico e neuroquímico. Indo de encontro a uma série de pesquisas, teorias e modelos que não consideram a integração entre aspectos cognitivos e emocionais, esses pesquisadores recorreram à fMRI para examinar e manipular a conjunção das tarefas cognitivas e dos estados mentais na atividade cerebral, focando especificamente no córtex pré-frontal lateral, "um local em potencial para a integração emoção-cognição”. Após o cumprimento das etapas necessárias à pesquisa, os neurocientistas chegaram à seguinte conclusão: "não apenas a emoção contribui para a relação do pensamento e comportamento, 
mas também a cognição pode contribuir para a regulação da emoção" (Gray, Braver \& Raichle, 2002, p. 4115-4116).

No processo neurocientífico de relativização do livre-arbítrio, é preciso considerar os experimentos de Joseph LeDoux, o qual, mais do que proclamar a cisão entre processos cognitivos de processos emocionais, pretende instituir a anterioridade dos processos emocionais na estruturação do comportamento moral. Daí porque, acredito, os experimentos de LeDoux não excluem necessariamente a ideia de que a emoção se relaciona em nível funcional com a cognição. Se processos emocionais e processos cognitivos têm percursos neurais próprios e particulares, também é verdade que, no âmbito dos raciocínios morais e da regulação do comportamento, há uma cooperação e integração funcional. Eis o que é preciso destacar: ainda que a cognição possa exercer papel relevante na regulação da emoção, nada mais justifica a antiga tese filosófica de que a razão é anterior ou primaz em relação às emoções. Mais que isso, as emoções estão no núcleo das relações entre pensamento e comportamento, regulando de maneira significativa nossos raciocínios morais. Esses apontamentos são particularmente relevantes para a discussão ética e filosófica, pois estabelece em novas bases o diálogo entre razão e emoção. Como sabemos, as relações entre razão e emoção constituem um problema filosófico bem definido desde os gregos, ainda que, sob a influência da cultura greco-romana e da cultura judaico-cristã, o modo como o Ocidente compreendeu a natureza dos afetos muito prejudicou a hipótese de um conhecimento mais sofisticado da mente humana. Com efeito, a insistência com que a racionalidade ética foi sobreposta aos afetos acabou reduzindo as emoções a dimensões que meramente refletem nossa incompletude e imperfeição.

\section{A contribuição da Neurociência Afetiva de Jaak Panksepp}

Com efeito, se, no âmbito das Neurociências, muitas são as questões que reclamam a conjunção e colaboração recíproca de diversos saberes, poucas destas, porém, despertam a mesma pluralidade de interesses que nossa (I) capacidade de gerar os mais diversos afetos, de (II) estruturar raciocínios morais e de (III) tomar decisões sob a influência das emoçôes. Refiro-me, decerto, aos principais problemas que justificam o elo entre Neurociências, Ética e Epistemologia: a natureza da consciência e o papel das emoções e dos processos cognitivos na tomada de decisões (decision-making), o que inclui as questôes do conhecimento, dos raciocínios morais, da ação e da normatividade. 
É nesse contexto que se inscreve meu interesse de sustentar e desenvolver a ideia de "Neurociência Afetiva" - de acordo com a vertente professada por Jaak Panksepp - como sendo um modelo ético que implica a seguinte compreensão: jamais saberemos o que são as emoções e como exercem influência sobre os raciocínios morais se ignorarmos o modo como o cérebro as produz. Tal compreensão é, sem dúvida, sustentada pela premissa, advogada por qualquer orientação em "Neurociência Afetiva", de que são os processos emocionais - incluindo os sentimentos subjetivamente experienciados que determinam, de maneira significativa, a "cadeia causal" de eventos que controlam as ações humanas em geral. E essa premissa está de acordo com a ideia de que distintos sistemas cerebrais geram comportamentos emocionais diferenciados, de onde resulta a possibilidade de uma taxonomia das emoções em seguras bases biológicas. E, por outro lado, a legitimação de uma natureza neurobiológica dos afetos é, sem dúvida, o que pode vir a engendrar a relevante compreensão de que são os processos emocionais que "fornecem vários tipos de valores internos naturais sob os quais muitas escolhas complexas comportamentais nos humanos são baseadas" (Panksepp, 1998, p. 14). Trata-se, nesse sentido, de uma importante relação entre processos emocionais básicos e raciocínios morais mais complexos.

Em tal compreensão está subsumida a exigência de delinear os processos que envolvem a decision-making na mesma medida em que supõem a interação e integração das emoções e da cognição em nível neural. De imediato, a melhor maneira de dar início a essa investigação supõe a tarefa de compreender os "sistemas operativos" que regulam as emoções básicas no cérebro, tendo em vista a seguinte premissa: os fenômenos psicológicos e o comportamento ético dependem de muitas e distintas atividades interativas que emergem no cérebro. Trata-se da tarefa sem a qual não podemos dar conta de duas questões filosóficas e interdependentes: o que são as emoções? Como se estrutura o raciocínio moral?

Esse paradigma é o que explica as razões pelas quais devemos recorrer à existência de vários e específicos sistemas psicocomportamentais que inerem à atividade neural, resultando daí a exigência de identificar e demarcar os principais sistemas emocionais da estrutura cerebral humana. Daí porque tenho proposto sustentar e desenvolver a ideia de "Neurociência afetiva": a discussão filosófica dos raciocínios morais, da ação e da normatividade pode se beneficiar dos resultados e postulados das pesquisas neurocientíficas, assim também gerando a possibilidade de discutir, do ponto de vista éticoepistemológico, as relações entre os comportamentos éticos e as características funcionais dos principais sistemas emocionais do cérebro. 
Com a evolução dos instrumentos de neuroimagem, que permitem o estudo do cérebro em pleno funcionamento, as Neurociências se depararam com a instigante possibilidade de aferir as principais áreas cerebrais envolvidas nos processos de decision-making e, ademais, com a possibilidade de compreender as consequências e ramificações desses processos complexos. Segundo Moll \& Oliveira-Souza (2008, p. 46),
A Neurociência cognitiva já pode explicar muitos dos mecanismos cerebrais que formam a base dos julgamentos morais e deliberações éticas. Estudos empíricos examinaram questóes tais como de que forma se constitui o senso de moralidade no cérebro de uma criança; de que maneira os diversos tipos de lesão cerebral afetam o julgamento moral, quais áreas do cérebro parecem estar em ação quando nos vemos diante de um impasse envolvendo questôes morais que nos desnorteiam e que rumos seguem os pensamentos em meio a esses dilemas. Basta realizar uma busca na internet para "cérebro e moralidade" para se ter uma ideia do quanto essa área de estudo é fértil e crescente.

Tal é a razão pela qual o surgimento das questões Éticas na Neurociência implica a compreensão de que a Moral e a Ética deixam de ser assuntos exclusivos da Filosofia e passam a também integrar o âmbito das Neurociências, surgindo daí um novo e profícuo campo de investigação, com características multidisciplinares. Ademais, conforme as investigações neurocientíficas incorporam significativas informações quanto às relações que se estabelecem entre raciocínio moral e emoção - a ponto de ser atualmente possível estruturar com mais eficácia a influência dos sentimentos sobre o que julgamos moral e imoral -, os estudos científicos da Ética adquirem maior envergadura e passam a determinar cada vez mais os rumos das discussóes éticas na contemporaneidade.

\section{Uma perspectiva naturalista dos dilemas e julgamentos morais}

Recentes descobertas científicas alimentam e têm alimentado alguns importantes e questionados estudos científicos sobre o comportamento ético e todas as polêmicas que constituem o debate contemporâneo: defende-se enfaticamente a existência nos homens de uma "rede neural moral especial" no interior de uma área cerebral repleta de circuitos que usam compostos bioquímicos relacionados à emoção e ao comportamento, dentre os quais a adrenalina e a serotonina. A mesma defesa se aplica à ideia de que o córtex pré-frontal é a área cerebral responsável pelo gerenciamento de algumas capacidades cognitivas que nos distinguem dos outros primatas, dentre as 
quais nossa sofisticada capacidade de planejamento racional e emocional. Trata-se da área cortical cujo amadurecimento tardio corresponde ao aprimoramento do raciocínio abstrato, da memória e da atenção, e especialmente à capacidade de inibir respostas emocionais. Indivíduos com lesões nessa área cortical, mais precisamente no córtex pré-frontal ventromedial (CPFVM), tendem a apresentar funcionamento cerebral distinto de outros indivíduos nos momentos em que são levados a tomar decisões e fazer opções que envolvem princípios éticos. Para tanto, neuroimagens, associadas com inúmeros testes neuropsicológicos, e no âmbito de rigorosos princípios metodológicos, tentam justificar essas relações entre raciocínios morais e emoções a partir do CPFVM como locus privilegiado de atuação.

Koenigsetal. (2007,p. 1) fizeram umadescoberta com consequênciaséticas significativas: lesões adquiridas no CPFVM aumentam significativamente, em situações de dilemas morais, a preferência por escolhas "pragmáticas" ou, como dizem, "utilitárias", desde que entendamos essa expressão no sentido mais vulgar e comum do termo. Eis como apresentam a pesquisa que revolucionou a investigação científica na área de decision-making e das relações entre raciocínios morais e emoções:

Os processos psicológicos e neurobiológicos subjacentes aos julgamentos morais têm sido o foco de muitos estudos empíricos recentes. É de sumo interesse saber se as emoções exercem papel causal nos julgamentos morais e, em paralelo, como as áreas do cérebro relacionadas à emoção contribuem para o julgamento moral. Aqui mostraremos que pacientes com danos no córtex pré-frontal ventromedial (CPFVM), uma região do cérebro necessária para a geração normal de emoções e, em particular, para as emoções sociais, produz um anormal padrão "utilitário" de julgamentos em dilemas morais. Em contrapartida, o julgamento dos afetados foi normal em outras classes de dilemas morais. Essas descobertas indicam que, para um seletivo número de dilemas morais, os afetados são críticos para julgamentos normais de certo e errado. Essas descobertas implicam o papel necessário da emoção na geração desses julgamentos.

Os julgamentos de dilemas pessoais morais dos indivíduos com lesão no CPFVM acabam favorecendo o bem-estar agregado em detrimento do bem-estar de menor número de indivíduos: essa postura pode ser considerada, em princípio, uma decisão meramente "aritmética" e, portanto, "racional", também entendido no sentido mais vulgar e comum 
do termo, isto é, sem a conotação de mérito que atribuímos, no Ocidente, à racionalidade.

Temos aí, de imediato, uma dissociação importante entre dilemas pessoais morais e julgamentos impessoais morais. Tal dissociação remete à cisão estabelecida por LeDoux (1996) entre processos emocionais (no caso, dilemas pessoais morais) e processos cognitivos (no caso, julgamentos impessoais morais). Essa lesão específica atua diretamente sobre os processos emocionais, os mesmos que são exigidos durante um dilema pessoal moral. Por outro lado, essa mesma lesão não engendra alterações significativas na capacidade cognitiva que é necessária para fazer julgamentos impessoais morais. Isso quer dizer que a manutenção da normalidade em julgamentos impessoais de certo e errado - que mais supõe nossas funções cognitivas que nossas funções emocionais -, diz respeito ao fato de que, nesse caso específico, os raciocínios morais sofrem pouca influência das emoções. Como o córtex pré-frontal ventromedial guarda relações mais enfáticas com a formação e constituição dos processos emocionais, suas lesões não alteram os julgamentos de fundo cognitivo estrito. No caso dos dilemas pessoais morais, a anormalidade no padrão de julgamentos é um indicativo claro da influência que as emoçôes podem exercer, nesse caso, sobre os raciocínios morais. Trata-se de um transtorno emocional capaz de modificar nossa própria estrutura cognitiva, nos casos em que a interação e integração emoção-cognição são imprescindíveis para o raciocínio moral em dilemas pessoais morais. Nesse caso, a normalidade da estrutura cognitiva reclama uma equilibrada integração emoção-cognição. Se julgamentos de dilemas morais por parte de indivíduos não afetados são marcados por essa integração equilibrada, é justamente porque a estrutura cognitiva não prescinde da influência das emoções.

Uma das mais importantes inserções em pesquisas sobre a personalidade e as emoções é a de Richard Davidson, cujo projeto de uma "biologia da personalidade e das emoções" supõe os papéis preponderantes do córtex préfrontal e da amígdala. Apoiado em estudos com a MRI, a fMRI e o PET, Davidson (2008, p. 192) fornece uma importante contribuição ética, mais especificamente sobre o processo de regulação de emoção no córtex préfrontal:

Em humanos e primatas não humanos, é indubitável que o córtex exerce importante papel na emoção. Pesquisas com humanos têm lançado luz sobre o papel de vários territórios do córtex pré-frontal (CPF) e, em especial, os que são cruciais para diferentes aspectos da emoção. O CPF é especialmente importante para regulação de emoção e para as diferenças individuais. Regulação de emoção se refere ao processo que realça, suprime ou mantém 
uma resposta emocional, enquanto que o estilo afetivo se refere a diferenças individuais consistentes nos parâmetros básicos da reatividade emocional e da regulação de emoção. A descoberta dos mecanismos de reatividade emocional fornece um caminho mais direto para o entendimento de como os fatores genéticos e experimentais podem operar sinergeticamente em um percurso final comum para formar personalidade e emoção.

Com efeito, embora o CPF seja usualmente considerado a província das funções cognitivas superiores, uma de suas funções mais conhecidas é a participação na geração de vários processos afetivos. Estudos neurofisiológicos, neuropsicológicos e com neuroimagens em humanos e outros primatas parecem indicar que o CPF é requerido para produção de sinais que se dirigem a outras regiōes cerebrais que guiam o comportamento. Do ponto de vista do comportamento ético, é particularmente significativo saber que recentes estudos eletrofisiológicos e com tecnologias de neuroimagem sugerem intrínsecas relações entre regiōes do CPF e a representação de recompensas e puniçôes (Davidson, 2003; Whalen, 1998). O estudo do funcionamento individual da distribuição dos setores de recompensa e punição fornece um entendimento relevante para compreensão do comportamento de cada indivíduo em função da dialética recompensa-punição e, sobretudo, para a compreensão dos transtornos de humor (Hettington et al., 2006).

Sobre o estudo acerca dos sistemas neurais de recompensa-punição, cuja implicação para as éticas contemporâneas é indiscutível, podemos dizer que grande parte do conhecimento adquirido acerca das associações entre memória e emoções resulta de estudos do condicionamento clássico do medo, na mesma medida em que o medo condicionado gera reaçôes que envolvem as mesmas características que as situações efetivamente ameaçadoras: imobilização dos movimentos, elevação da pressão arterial e da frequência cardíaca, superficialidade da respiração, assim como facilidade e rapidez para o sobressalto. Do ponto de vista da constituição da memória emocional, como se sabe desde o surgimento dos laboratórios de Psicologia Experimental, cumpre ressaltar que, no medo condicionado, há uma associação entre um estímulo relativamente neutro (o estímulo condicionado, EC) e um evento aversivo, ao qual é parelhado, em dado momento, por uma razão que pode ser objetiva ou meramente idiossincrática.

No condicionamento ao medo, os neurônios de algumas regióes cerebrais, que são responsáveis pela associação de um evento a uma resposta condicionada, tendem a interpretar certos estímulos de maneira 
diferenciada. Há muito pouco tempo, foram descobertos os principais componentes desses circuitos da memória emocional. Antes, o estudo do condicionamento clássico do medo enfatizava mais diretamente o papel do córtex auditivo, e, depois, o tálamo e o mesencéfalo, no tanto quanto se relacionam de maneira direta com algumas zonas subcorticais. Atualmente, porém, sabe-se que a memória emocional e, subsequentemente, os circuitos neurais do medo supóem alguns mecanismos neuro-hormonais, neurofisiológicos, neuroquímicos e neuroelétricos, assim como o papel preponderante dos núcleos central e lateral (mais especificamente, o dorsolateral) da amígdala, no tanto quanto participam dos processos emocionais de forma decisiva.

Os núcleos da amígdala participam dos comportamentos emocionais mediante atuação significativa no circuito de condicionamento do medo, e em função de sua conexão com inúmeras regiôes do tronco cerebral que comandam específicas e relevantes reações comportamentais. O sistema do medo não é, como se supõe usualmente, um sistema que resulta da experiência do medo. Antes, trata-se de um circuito neuronal que "detecta o perigo e produz respostas que maximizam a probabilidade de sobrevivência a situações perigosas, pelo caminho mais benéfico" (LeDoux, 1996, p. 35). Trata-se, na verdade, da ideia de que nossa emoção mais primitiva é a que cria o comportamento defensivo: "Para sobreviver, os animais e os homens precisam aprender desde cedo sobre as coisas e os lugares que potencialmente oferecem algum tipo de perigo" (LeDoux, 1995, p. 1029). Crendo que os comportamentos emocionais, como, por exemplo, os comportamentos defensivos, evoluíram de maneira independente, e antes dos sentimentos conscientes, LeDoux defende que representam a operação do sistema cerebral a qual independe da consciência, razão pela qual são designados de sentimentos inconscientes. LeDoux se inscreve na tradição contemporânea, junto com Paul Whalen, segundo a qual a compreensão de certas emoções, como o medo e a ansiedade, depende, em alto grau, da explanação das funções da amígdala, que é cada vez mais conhecida por sua independência em relação aos processos conscientes.

Nesse sentido, nada mais natural do que ser levado à seguinte indagação: tendo em vista a independência das emoções em relação aos processos conscientes, mesmo no âmbito de convincentes relações de interação e integração entre raciocínios morais e emoções, como pensar qualquer modelo ético na contemporaneidade? Nossos atos e escolhas são mais determinados por processos emocionais básicos do que por decisões conscientes? Enfim: o que resta de voluntário no homem? 


\section{Considerações finais}

De fato, muitos são os filósofos e neurocientistas que têm se debruçado sobre a questão das decisões éticas. Certas questões, no entanto, ainda dependem de profundas e futuras investigações, como mostram Walter \& Schleim (2008, p. 44): (I) qual a contribuição de cada nó da "rede da moral" no cérebro? (II) Qual o papel desempenhado por aspectos sociais e autorreferentes nas decisões de cunho moral? (III) Quais princípios morais são inatos e quais podem ser aprendidos? (IV) Será que tomografias cerebrais e outros procedimentos por imagem podem ajudar a avaliar o potencial de risco de criminosos individualmente? Sem dúvida, já temos um primeiro grande passo para a resolução de tais dificuldades: o reconhecimento das emoções como peças-chave para a compreensão da mente humana. Como advertem Walter \& Schleim (2008, p. 45), "experimentos dos fisiologistas da moral têm se mostrado frutíferos. Eles apontam para processos que não seriam reconhecíveis apenas pela reflexão e observação". Por enquanto, concluem, "pode-se afirmar que a racionalidade abstrata parece desempenhar um papel claramente menos importante na ética do dia a dia do que o de nossos sentimentos”.

\section{Referências}

Aristóteles. (2000a). Ética Nicomáquea. Madrid: Gredos.

Aristóteles. (2000b). Ética Eudemia. Madrid: Gredos.

Davidson, R. (2003). Affective neuroscience and psychophysiology: toward a synthesis. Psychophysiology, 40, 655-665.

Davidson, R. (2008). Toward a Biology of Personality and Emotion. Annals New York academy of sciences, 1 (1), 191-207.

Gray, J.; Braver, T. \& Raichle, M. (2002). Integration of emotion and cognition in the lateral prefrontal cortex. PNAS, 99 (6), 4115-4120.

Herrington, J.; Koven, N.; Miller, G. \& Heller, W. (2006). Mapping the Neural Correlates of Dimensions of Personality, Emotion, and Motivation. In: T. Canli. Biology of personality and individual differences. (pp. 133-156). New York: The Guilford Press.

Hauser, M. (2006). Moral minds. How nature designed our universal sense of right and wrong? New York: Harper Collins. 
Koenigs, M.; Young, L \& Damasio, A. (2007). Damage to the prefrontal cortex increases utilitarian moral judgments. Nature, 446, 908-911.

LeDoux, J. (1995). Fear conditioning enhances short-latency auditory responses of lateral amygdala neurons: parallel recordings in the freely behaving rat. Neuron, 15, 1029-1039.

LeDoux, J. (1996). The Emotional Brain. New York: Simon \& Schuster.

Moll, J.; Oliveira-Souza, R. \& Eslinger, P. (2003). Morals and the human brain: a working model. Neuroreport, 1 (3), 299-305.

Moll, J. \& Oliveira-Souza, R. (2007). Moral judgments, emotions and the utilitarian brain. Trends in Cognitive Science, 30 (10), 1-3.

Moll, J. \& Oliveira-Souza, R. (2008). Primeiro sentimos, depois julgamos. Mente e cérebro, 1 (187), 46-51.

Naqvi, N. \& Bechara, A. (2008). The hidden island of addiction: the insula. Trends in neurosciences Elselvier, 32 (1), 55-67.

Panksepp, J. (1998). Affective Neuroscience: the foundations of human and animal emotions. New York: Oxford University Press.

Walter, H. \& Schleim, S. (2008). Pelos trilhos da Ética. Mente e cérebro, 1 (187), 40-45.

Whalen, J. P. (1998). Fear, vigilance, and ambiguity: initial neuroimaging studies of the human amygdala. Current Directions in Psychological Science, 7 (6), 177-188. 